\title{
Synthesis and Characterization of Porous Sulfur/MWCNTs Composites with Improved Performance and Safety as Cathodes for Li-S Batteries
}

\author{
Andrea Strakova Fedorkova ${ }^{1, *}$, Tomas Kazda ${ }^{2}$, Katarina Gavalierova ${ }^{1}$, Pedro Gomez-Romero ${ }^{3}$, \\ Elena Shembel \\ ${ }^{1}$ Institute of Chemistry, Faculty of Science, P.J. Šafárik University, Moyzesova 11, \\ 04154 Košice, Slovakia \\ ${ }^{2}$ Department of Electrical and Electronic Technology, Faculty of Electrical Engineering and \\ Communication, Brno University of Technology, Technicka 10, 61600 Brno, Czech Republic \\ ${ }^{3}$ Institut Català de Nanociència i Nanotecnologia, ICN2, CIN2 / Consejo Superior de Investigaciones \\ Científicas (CSIC), Campus UAB, E-08193 Bellaterra, Barcelona, Spain \\ ${ }^{4}$ Ukrainian State University of Chemical Technology, Gagarin Ave. 8, Dnipropetrovsk, Ukraine, \\ 49005
}

*E-mail: andrea.fedorkova@upjs.sk

doi: $10.20964 / 2018.01 .67$

Received: 30 September 2017 / Accepted: 24 November 2017 / Published: 16 December 2017

Sulfur-carbon (S-C-MWCNTs) composites and sulfur-LiFePO 4 (S-LFP-MWCNTs) composites were synthesised with MWCNTs additive by sulfur sublimation and solid state reaction. As prepared materials are characterized with scanning electron microscopy, thermogravimetry, FTIR, elemental analysis, XPS, cyclic voltammetry and galvanostatic charge/discharge tests. The composite S-LFP cathode with MWCNTs additive shows improved discharge capacity and performance. It shows an initial discharge capacity of $1167 \mathrm{mAh} / \mathrm{g}$-sulfur, or $70 \%$ of theoretical capacity. The discharge capacity measured after 20 cycles for S-LFP-MWCNTs composite cathode was $80 \%$ of the initial capacity and remained stable. After 160 charge/discharge tests, the cathode displays a stable capacity of 561 $\mathrm{mAh} / \mathrm{g}$-sulfur at the C-rate of $0.2 \mathrm{C}$. Combination of sulfur, $\mathrm{LiFePO}_{4}$ and $\mathrm{MWCNTs}$ prevents aggregation and volume change of the cathode particles and improves the conductivity and electrochemical stability during the long-term cycling. 3-D FTIR spectroscopy measurements confirmed improved chemical stability and safety of sulfur composites also at higher temperatures.

Keywords: Sulfur composite cathode, Lithium batteries, $\mathrm{LiFePO}_{4}$, multi-wall carbon nanotubes

\section{$\underline{\text { FULL TEXT }}$}


(C) 2018 The Authors. Published by ESG (www.electrochemsci.org). This article is an open access article distributed under the terms and conditions of the Creative Commons Attribution license (http://creativecommons.org/licenses/by/4.0/). 